\title{
POLYETHYLENE TEREPHTHALATE (PET) BOTTLE WASTES POLYMER TILES: WEAR-ABRASION RESISTANCE AND MECHANICAL PROPERTIES
}

\author{
OMOSEBI O$^{1}$, NOOR ABAS ${ }^{1}$, and SULAIMON YAHAYA ${ }^{1}$ \\ ${ }^{1}$ Universiti Sains Malaysia
}

March 15, 2021

\begin{abstract}
Managing plastic waste is a global challenge that challenges our ecosystem's health due to its high production rate and nonbiodegradability. However, it is necessary to ensure that PWs are properly managed to reduce the environmental pollution associated with their incineration and dumping in landfills. This study explores the possibility of utilizing polyethylene terephthalate (PET) waste bottles and river sand to produce floor tiles. The flammability, abrasion resistance, mechanical strength, and strong acid/base resistance of the produced PET-based floor tiles were investigated as well as the micro-structural interface of the PET plastic waste and sand. The PET waste was used at different proportions $(100 \%, 90 \%, 70 \%, 50 \%$, and $30 \%)$ by sand weight. The assessment of the materials' physical and mechanical properties has shown that, in terms of material density, strength, abrasion, and flame resistance, the floor tiles produced with $30 \%$ PET content performed better than those produced with the other PET contents. It showed the highest compressive strength value $(19.72 \mathrm{~N} / \mathrm{mm} 2)$. The observed compressive strength values in this study were significantly higher than the recommended 28-day residential concrete value of $17 \mathrm{~N} / \mathrm{mm} 2$; $\mathrm{p}<0.05$. From the obtained results, the PET floor tiles showed poor water absorption performance compared to pure cement and ceramic floor tiles (The lowest water absorption value of $0.12 \%$ was found in tiles made of $100 \%$ PET waste). Microscopic analysis of the interface region (plastic-binder) showed adhesion between the plastic and sand components of the PET-based floor tiles, as well as voids in direct proportion to the PET content. The PET floor tiles also showed good resistance to acid and base solutions of different strengths. In conclusion, PET waste bottles can be used as cement replacement to produce durable and abrasive resistant floor tiles for both residential and commercial uses.
\end{abstract}

\section{Hosted file}

Wear-Abrasion_resistance_of_PET_floor_tile_(J.Paper).pdf available at https://authorea.com/ users/401603/articles/513638-polyethylene-terephthalate-pet-bottle-wastes-polymer-tileswear-abrasion-resistance-and-mechanical-properties

\section{Hosted file}

Tables [PFT] (J. paper).pdf available at https://authorea.com/users/401603/articles/513638polyethylene-terephthalate-pet-bottle-wastes-polymer-tiles-wear-abrasion-resistance-andmechanical-properties

\section{Hosted file}

Figures [PFT] (J. Paper).pdf available at https://authorea.com/users/401603/articles/513638polyethylene-terephthalate-pet-bottle-wastes-polymer-tiles-wear-abrasion-resistance-andmechanical-properties 